\title{
VANDAL LOADS AND INDUCED VIBRATIONS ON A FOOTBRIDGE
}

\author{
Elsa CAETANO \\ Assistant Professor \\ University of Porto \\ Porto, Portugal
}

\author{
Álvaro CUNHA \\ Associate Professor \\ University of Porto \\ Porto, Portugal
}

\author{
Carlos MOUTINHO \\ Assistant \\ University of Porto \\ Porto, Portugal
}

\section{Summary}

The paper describes a study to characterise vertical dynamic loads and induced effects on a footbridge. The study comprehends the development of a numerical model to characterise the dynamic behaviour of the footbridge, which is experimentally validated and used to numerically simulate the response induced by groups of pedestrians synchronised at critical bridge frequencies. The vandal load associated with a single pedestrian is characterised and the response is calculated considering the measured load, and compared with the measured response to the excitation induced by a single pedestrian or a group with varying dimension. The definition of a general load model for vandal excitation is discussed.

Keywords: Footbridge; Vibrations; Vandal Loads; Stress-ribbon bridge

\section{Introduction}

The problem of footbridge vibrations induced by pedestrians is in general analysed from a point of view of comfort. This strategy stems from the idea that pedestrians are not able to cause damage into a footbridge. Such a conclusion was issued by several authors in the past, like Wheeler [1], whose results were based on the investigation of 22 footbridges, and is also corroborated by the long and rich, in terms of life losses, history of footbridge collapses. In effect, most of the reported failures seem to be related with insufficient carrying capacity, or with damage or insufficient resistance of certain important connecting devices, rather than dynamic effects of human loads [2].

The trend to construct progressively lighter and slender footbridges, also characterised frequently by very low damping, is responsible for the proneness of modern footbridges to vibrations. Considering the easiness of resonance excitation for certain structures, it becomes questionable whether it is possible or not for a group of persons to affect the structural integrity of a footbridge. Such a situation is reported for a footbridge in China in 1994, in which a severe structural failure has been provoked by a group of students who tried to excite a footbridge for fun, causing the death of 38 persons [3]. The current paper describes a study developed to appropriately characterize the potential for structural collapse of a stress-ribbon footbridge excited by synchronized groups of vandals. The footbridge, located in the campus of the Faculty of Engineering of Porto, has been extensively investigated in the past, in order to characterise its dynamic behaviour and the lively response to different types of dynamic loads. The current study attempts to characterise intentional loads applied to deliberately induce resonance effects, here designated as "vandal loads", and the corresponding effects on the behaviour of the footbridge, investigating possible structural collapse conditions. The measured force applied by a single pedestrian is characterised and compared with load models defined in the past. The measured response to single and group excitation is used for back-calculation of group loads.

Complementary numerical simulations are developed in order to investigate possible structural collapse conditions. It is observed that, due to defaults in the construction procedure, the bridge exhibits already a certain degree of damage that is essentially associated with cracks at the joints of precast segments. Although the crack width is expected to progress, it is concluded that very unlikely can a group of vandals motivate the collapse of the bridge, as the accelerations required 


\section{Footbridge 2005 - Second International Conference}

would be so significant that they would compromise the equilibrium of people and therefore imply an interruption of the excitation long time before the occurrence of a failure.

\section{Characterisation of the bridge}

\subsection{General description}

The footbridge under analysis integrates the new Campus of the Faculty of Engineering of the University of Porto, providing a pedestrian link between the main buildings and the student's canteen and parking areas (Fig. 1). It was designed by ENCIL [4] and is characterised as a stress-ribbon footbridge formed by two spans of $28 \mathrm{~m}$ and $30 \mathrm{~m}$. The cross-section is formed by 4 prestressing cables embedded in a reinforced concrete approximately rectangular crosssection with external design dimensions of $3.80 \mathrm{~m} \times 0.15 \mathrm{~m}$ formed after in-situ casting of concrete over $1 \mathrm{~m}$ long precast segments hanging from the tensioned cables. A more complete description of the bridge is presented in [5].

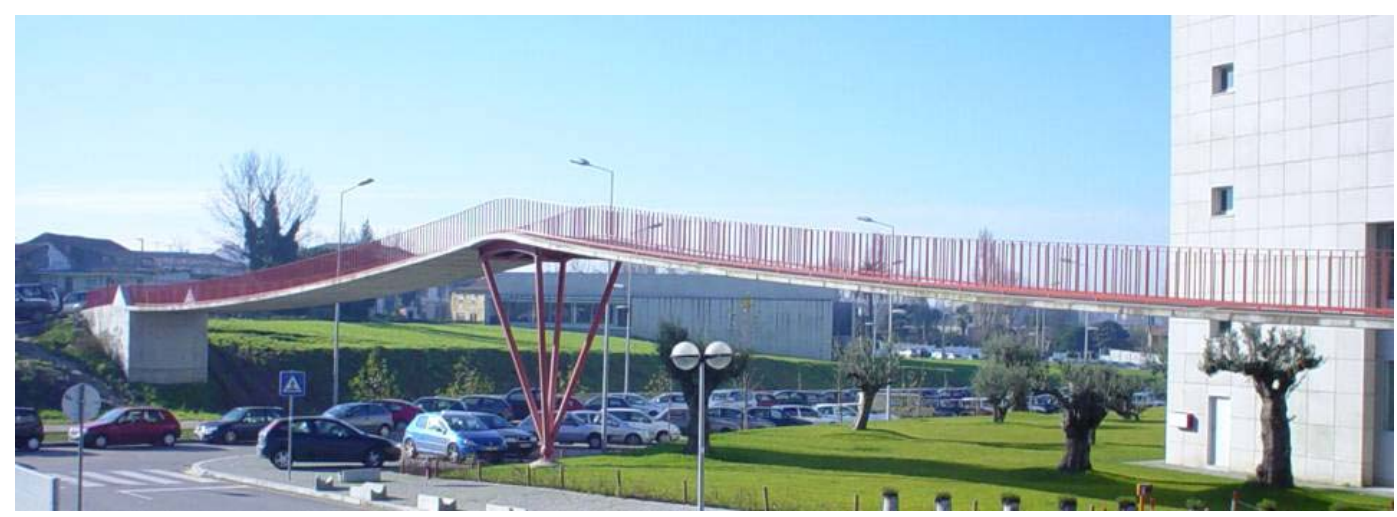

Fig. 1 View of footbridge

\subsection{Static behaviour}

Previous experimental and numerical studies developed on the bridge [5] illustrated the complex structural behaviour and the significant dependence upon the construction procedure followed. Therefore the numerical model was developed trying to simulate the sequence of construction. Using a nonlinear geometric formulation, a finite element mesh was formed initially by a set of tensioned truss elements that were loaded progressively, suffering large deformations. Beam elements connecting the same nodes were then activated to simulate the concrete hardening. Linear behaviour was assumed at this stage, considering the tangent stiffness matrix calculated at the deformed configuration.

Thorough topographic and vibration surveys and the update of the finite element model have provided important conclusions concerning the structural behaviour of the footbridge. It was first observed that the static profile differs slightly from the predicted at design phase, evidencing a maximum deviation by excess of deformation of around $0.20 \mathrm{~m}$ close to the middle of the largest span. It was suggested that this profile might be associated with a thicker cross section than the one defined in the design. That fact was confirmed and it was estimated that the deck mass is higher by $20 \%$ than the corresponding to the design. However it was noticed that the $0.20 \mathrm{~m}$ excess of deformation could not be entirely due to the increase of deck mass, it was necessary that the initial cable tension was lower than the design value to achieve the current profile. Iterative calculations led to an initial tension of $2034 \mathrm{kN}$ instead of $3000 \mathrm{kN}$, meaning that important loss may have occurred either during or at the end of construction. Finally it was shown that the catenary bridge has an intermediate behaviour between a tensioned cable and a beam structure. Moreover, the validation of the numerical model considering the measured natural frequencies and modal shapes demanded that partial rotations were allowed between successive precast segments, meaning the existence of cracks at those critical sections. This idea is reinforced by the fact that contrary to the design prescriptions, no final prestressing of the cables was applied at the end of construction, and the joints between precast segments were not sealed. Given the slight thickness of the deck, it is then expected that tensile stresses accumulated at those joints may have originated cracks. 


\section{Numerical Model and Experimental Validation}

In order to capture the bridge behaviour in the lateral direction, a three-dimensional model was developed, simulating again the construction sequence, and employing a set of 8-node shell elements to discretise the deck and the joints.

Two series of parallel truss elements $3.80 \mathrm{~m}$ distant are used to idealise the four cables. These elements are tensioned considering the initial force of around $2000 \mathrm{kN}$, and submitted to their weight and the weight of the concrete deck, applied progressively from the abutments to the central pier. After deformation, beam and shell elements are activated connecting the two parallel sets of cable nodes. Beam and shell elements with a length of $0.99 \mathrm{~m}$ alternate with beam and shell elements $0.01 \mathrm{~m}$ long, the later simulating the joints between precast elements. The properties of these elements were iteratively modified till the natural frequencies and mode shapes approximated the measured values and a slight modification of the initial cable tension was performed in order to achieve the measured profile. Using this procedure, different reduction factors of area and inertia were obtained with respect to the corresponding intact cross sections. Shell elements of $3.80 \times 0.10 \mathrm{~m}$ cross section were used to simulate the region where precast elements exist, and the total area and inertia considered (including beam elements) are defined as $0.56 A_{p}$ and $0.64 I_{p}, A_{p}$ and $I_{p}$ representing the area and inertia of the intact cross section in that region. For the joints, shell elements $3.80 \times 0.034 \mathrm{~m}$ were used, the total area and inertia being $0.25 \mathrm{~A}_{\mathrm{j}}$ and $0.48 \mathrm{I}_{\mathrm{j}}, \mathrm{A}_{\mathrm{j}}$ and $\mathrm{l}_{\mathrm{j}}$ representing the area and inertia of the corresponding intact cross section.

Table 1 Calculated and identified natural frequencies and damping coefficients

\begin{tabular}{cccccc}
\hline $\begin{array}{c}\text { Mode } \\
\text { no. }\end{array}$ & $\begin{array}{c}\text { Calculated } \\
\text { frequency } \\
\mathbf{( H z )}\end{array}$ & $\begin{array}{c}\text { Identified } \\
\text { frequency } \\
\mathbf{( H z )}\end{array}$ & $\begin{array}{c}\text { Damping } \\
\mathbf{( \% )}\end{array}$ & $\begin{array}{c}\text { Calculated modal } \\
\text { mass (ton)* }\end{array}$ & Type of mode \\
\hline 1 & 0.940 & 0.972 & 1.07 & 44.967 & First symmetric (two spans, opposite phase) \\
2 & 2.101 & 2.072 & 1.51 & 36.400 & Second anti-symmetric (L=30m) \\
3 & 2.152 & 2.043 & 1.40 & 36.583 & First symmetric (two spans, in-phase) \\
4 & 2.234 & 1.960 & 1.10 & 42.769 & First lateral (two spans) \\
5 & 2.344 & 2.382 & 1.72 & 21.177 & Second anti-symmetric (L=28m) \\
6 & 3.736 & 3.590 & 1.78 & 22.627 & Second symmetric (L=30m) \\
7 & 3.875 & - & - & 29.311 & First torsional (two spans, L=30m dominant) \\
8 & 4.188 & 4.165 & 2.00 & 21.132 & Second symmetric (L=28m) \\
9 & 4.200 & - & - & 27.790 & First torsional (two spans, L=28m dominant) \\
10 & 5.761 & 5.461 & 1.92 & 23.237 & Third anti-symmetric (L=30m) \\
\hline
\end{tabular}

${ }^{*}$ referred to unit modal displacements at the antinodes

$\mathrm{F}=2.101 \mathrm{~Hz}$

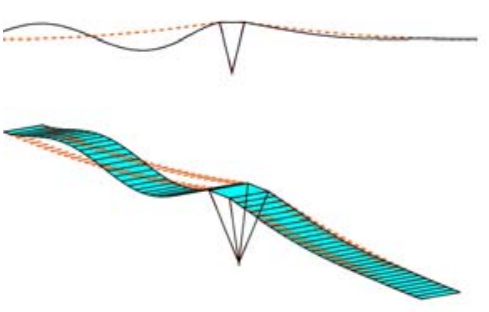

$\mathrm{F}=2.234 \mathrm{~Hz}$
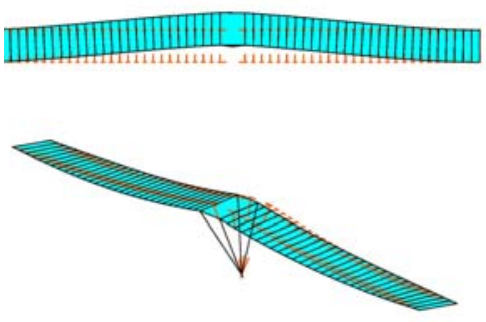

$\mathrm{F}=2.152 \mathrm{~Hz}$

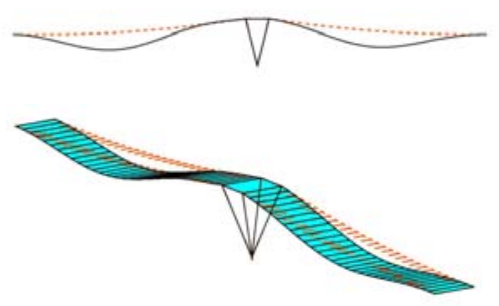

$\mathrm{F}=2.344 \mathrm{~Hz}$
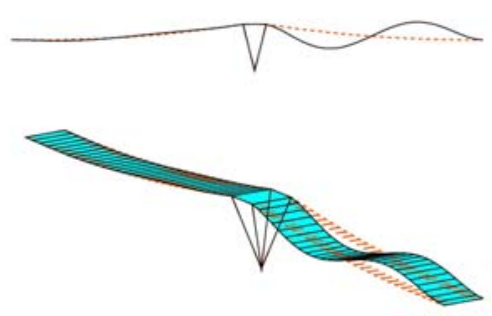

Fig. 2 Examples of calculated modal shapes 
Table 1 resumes the resulting natural frequencies and modal shapes, and presents a comparison with the corresponding values identified on the basis of a recent modal survey [6]. The classification of vibration modes as symmetric and antisymmetric is used for easier understanding of the structural behaviour. In practice, as the structure is not exactly symmetric, this characterisation is only approximate. Fig. 2 shows the modal configurations associated with the most critical modes from the point of view of pedestrian excitation.

The analysis of Table 1 shows that the three-dimensional model is slightly stiffer for the lowest vibration modes (except the first) and more flexible for the higher order modes. The closeness between natural frequencies, the agreement between calculated and identified modal configurations [5,6], and the reduced mechanical properties of the elements forming the model, evidence the existence of a considerable level of cracking along the deck, which seems particularly concentrated at the joints between precast segments. As for the possible contribution of the handrail, it is thought that given the existence of several joints along the footbridge, eventually only the first vibration mode is slightly affected.

\section{Vandal loads}

The deliberate excitation to resonance of a footbridge results from a first evidence of liveliness and can be achieved in different forms, depending on the characteristics of induced vibration: lateral, vertical bending or torsional.

For vertical vibrations, "skipping on the spot", also designated as "jumping", is the easiest way to induce resonance. Another possibility is "bobbing", also designated as "bending knees excitation". Contrary to the first case, for this excitation type both feet of the subject are permanently in contact with the ground. Figure 3 illustrates the force measured through a set of load cells on a small stiff platform induced by the same subject for the two different situations. The peak amplitude of applied force depends on the frequency of excitation and is generally lower for bending knees excitation than for jumping. However, when considering group excitation, it is observed that the degree of synchronisation amongst pedestrians is higher for this situation than for jumping, therefore it can happen that higher loads are applied to the bridge using this type of excitation.

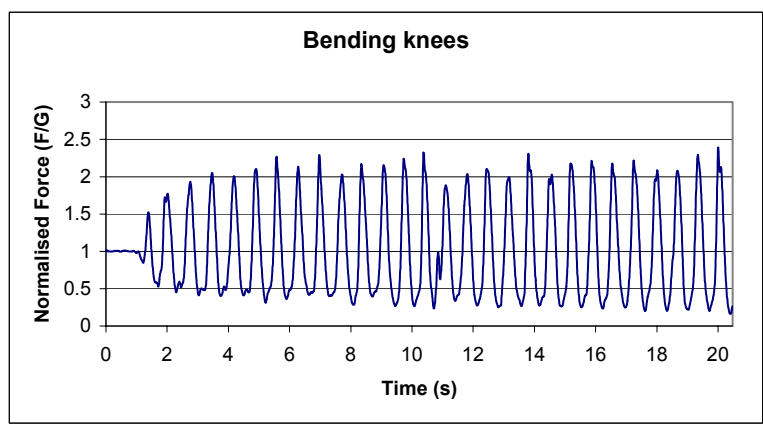

(a)

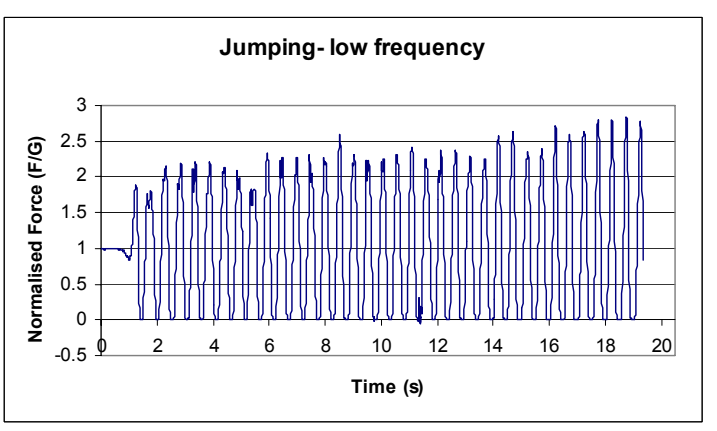

(b)

Fig. 3 Vertical excitation induced by (a) Bending knees excitation; (b) Jumping.

\subsection{Single pedestrian load model}

The "half-sine model" defined by Bachmann [7] for jogging and skipping in the range $1.8 \mathrm{~Hz}-3.4 \mathrm{~Hz}$ is defined by

$$
F_{p}(t)=\left\{\begin{array}{lr}
k_{p} \cdot G \cdot \sin \left(\frac{\pi t}{t_{p}}\right) & t \leq t_{p} \\
0 & t_{p}<t \leq T_{p}
\end{array}\right.
$$

where $k_{p}$ is designated as the dynamic impact factor and defined as $k_{p}=F_{p \max } / G, G$ is the weight of the pedestrian, typically defined as $800 \mathrm{~N}$, $\mathrm{t}_{p}$ is the contact duration of the feet with the ground, and $T_{p}=1 / f_{p}$ is the jumping period. In this model, the impact factor is defined by

$$
k_{p}=\pi /\left(2 \cdot \frac{t_{p}}{T_{p}}\right)
$$

as a result of the condition of constant potential energy. Figure 4(a) represents the idealised force superimposed with the 
measured force associated with an average jumping frequency of $2.7 \mathrm{~Hz}$. The quantities $k_{p}, t_{p}$ and $T_{p}$ are derived based respectively on the average of peak force, contact duration (determined by the time interval with load amplitude lower than $1 \%$ the average peak force), and on the FFT frequency associated with the first harmonic peak of the load record. Figure 4(b) represents the variation with $t_{p} / T_{p}$ of the impact factor defined by (2) as well as the measured values based on a series of jumping tests at different step frequencies. Table 2 systematises the characteristics of measured forces expressed in terms of the contribution in the first three harmonics, average impact factor and contact duration, and average ratio $t_{p} / T_{p}$. It is confirmed that the contact duration with the ground is higher than $0.15 \mathrm{~s}$, as specified by Bachmann [7]. This duration increases with the decrease of frequency and represents more than $60 \%$ of the step period for all cases, much higher than the values of 25\%-33\% specified in BS6399 [8] for normal and high jumping.

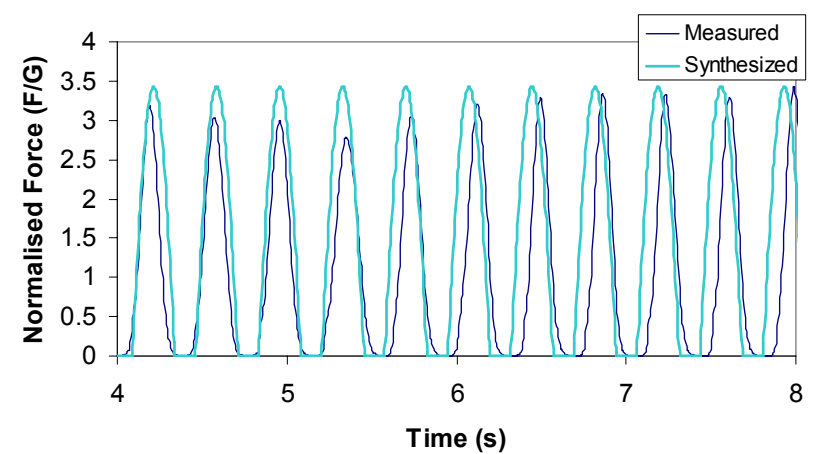

(a)

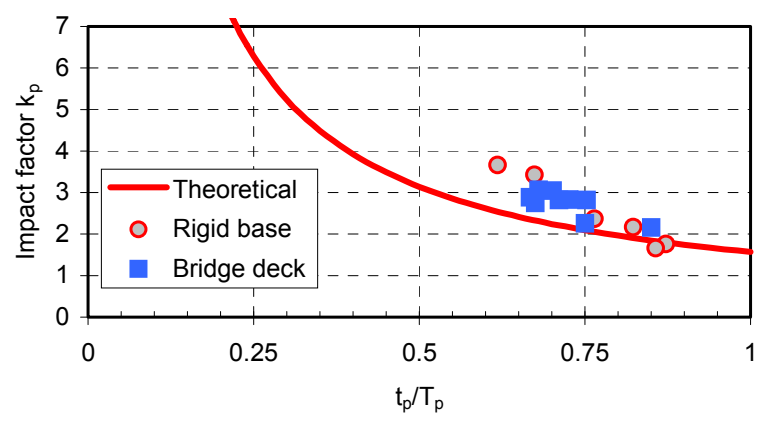

(b)

Fig. 4 Half-sine load model for jumping: (a) measured and synthesized force for jumping frequency of 2.7Hz; (b) Impact factor, load model and measured.

Table 2 Characteristics of measured force

\begin{tabular}{|c|c|c|c|c|c|c|}
\hline $\begin{array}{l}\text { Type of } \\
\text { excitation }\end{array}$ & $\begin{array}{c}\text { Contribution in } 1 \text { st } \\
\text { harmonic }\end{array}$ & $\begin{array}{l}\text { Contribution in } \\
2^{\text {nd }} \text { harmonic }\end{array}$ & $\begin{array}{c}\text { Contribution in } 3^{\text {rd }} \\
\text { harmonic }\end{array}$ & $\begin{array}{c}\text { Impact factor } \\
k_{p}\end{array}$ & $t_{p}$ & $t_{p} / T_{p}$ \\
\hline Bending knees & $1.46 \mathrm{~Hz}(0.68)$ & $2.88 \mathrm{~Hz}(0.14)$ & $4.39 \mathrm{~Hz}(0.04)$ & 2.12 & & \\
\hline Jumping high 1 & $2.69 \mathrm{~Hz}(0.98)$ & $5.37 \mathrm{~Hz}(0.34)$ & $8.10 \mathrm{~Hz}(0.06)$ & 3.43 & 0.250 & 0.674 \\
\hline Jumping high 2 & $2.49 \mathrm{~Hz}(1.12)$ & $4.98 \mathrm{~Hz}(0.48)$ & $7.47 \mathrm{~Hz}(0.12)$ & 3.66 & 0.248 & 0.618 \\
\hline Jumping low 1 & $1.95 \mathrm{~Hz}(1.06)$ & $3.91 \mathrm{~Hz}(0.14)$ & $5.81 \mathrm{~Hz}(0.06)$ & 2.37 & 0.392 & 0.764 \\
\hline Jumping low 2 & $1.90 \mathrm{~Hz}(0.70)$ & $3.91 \mathrm{~Hz}(0.06)$ & $5.76 \mathrm{~Hz}(0.04)$ & 2.17 & 0.433 & 0.823 \\
\hline Jumping low 3 & $1.71 \mathrm{~Hz}(0.46)$ & $3.42 \mathrm{~Hz}(0.14)$ & & 1.76 & 0.510 & 0.872 \\
\hline Jumping low 4 & $1.46 \mathrm{~Hz}(0.44)$ & $2.98 \mathrm{~Hz}(0.16)$ & $4.49 \mathrm{~Hz}(0.04)$ & 1.66 & 0.587 & 0.857 \\
\hline
\end{tabular}

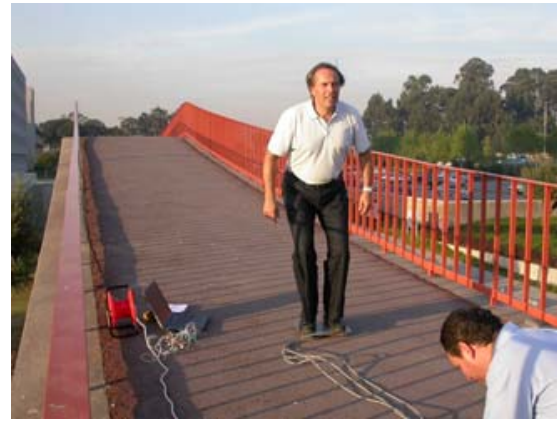

(a)

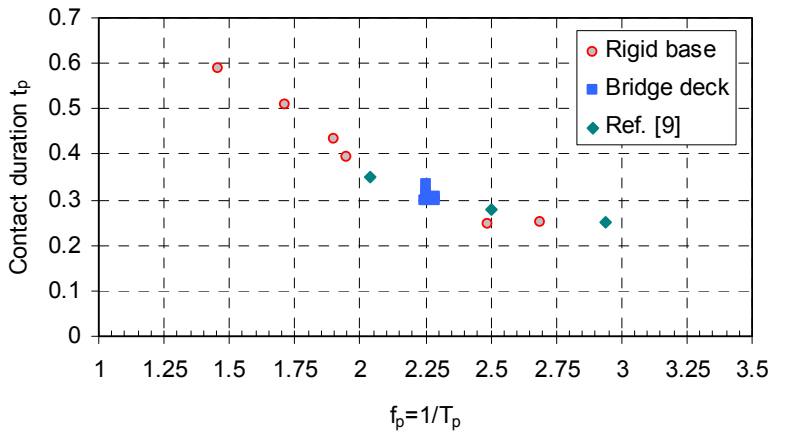

(b)

Fig. 5 (a) Measurement of jumping load on a load cell installed at an antinode of a critical mode; (b) Variation of contact duration with frequency of jumping for measurements performed on a rigid platform, on the bridge deck and on rigid surface by [19] 
It is questioned whether a vibrating platform can change the impact factor $k_{p}$ as a consequence of the increase of the contact duration between the feet and the ground. This situation could be critical at resonance and would result in a lower value of $k_{p}$. Figure $4(b)$ represents some results of load measurements performed with the set of load cells and rigid platform installed on the bridge deck at the antinodes of the vibration modes 2 and 3 (see Table 1 and Figure 5). The jumping frequency was measured in the range $2.15 \mathrm{~Hz}-2.29 \mathrm{~Hz}$, slightly away from resonance, and the peak acceleration recorded at the load cell location was in the order of $0.3 \mathrm{~m} / \mathrm{s}^{2}$, corresponding to a dynamic displacement of about $1 \mathrm{~mm}$. For this range of displacements no significant variation in the value of $k_{p}$ was observed, and the contact duration between the feet and ground, represented in Figure $5(b)$ does not show a clear increase, meaning that eventually only for situations of resonance with high amplitude of vibration can that duration increase.

The listed values are in good agreement with the results of a more complete study [9] developed on a rigid/ movable platform involving a group of 6 to 10 sport students performing different activities, in which the following parameters have been identified: $T_{p}=0.34 \pm 0.03 ; t_{p}=0.29 \pm 0.07 ; k_{p}=3.00 \pm 0.52$. Figure $5(b)$ includes some values from this reference, corresponding to equivalent tests developed at different natural frequencies. Also as a result of this research, it is observed that a description of the jumping load based on the Hanning function provides a much better approximation to a typical impulse load than the half-sine model. $F_{p}(t)$ is then defined as

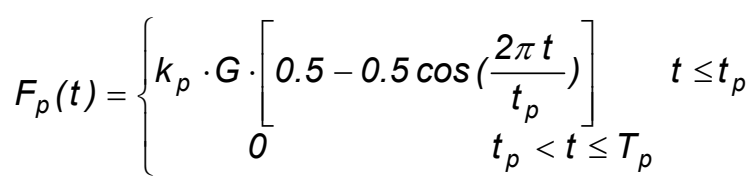

Figure 6 (a) shows the approximation by the half-sine and the Hanning models of a typical measured impulse function associated with a jumping frequency of $2.7 \mathrm{~Hz}$, evidencing the better quality of the fit. Using this load model, the impact factor $k_{p}$ can be re-calculated as

$$
k_{p}=2 /\left(\frac{t_{p}}{T_{p}}\right)
$$

Expression (4) is represented in Figure 6(b) and compared both with the one resulting from the half-sine model and with experimental values above referred. It can be concluded that, except for low jumping frequencies $(1.46 \mathrm{~Hz}$ and $1.71 \mathrm{~Hz})$, the measured values of $k_{p}$ fit better curve (4). It should be noted that for those lower frequencies more irregular impulses are measured, which exhibit two close peaks, evidencing a two-step contact of the feet with the ground.

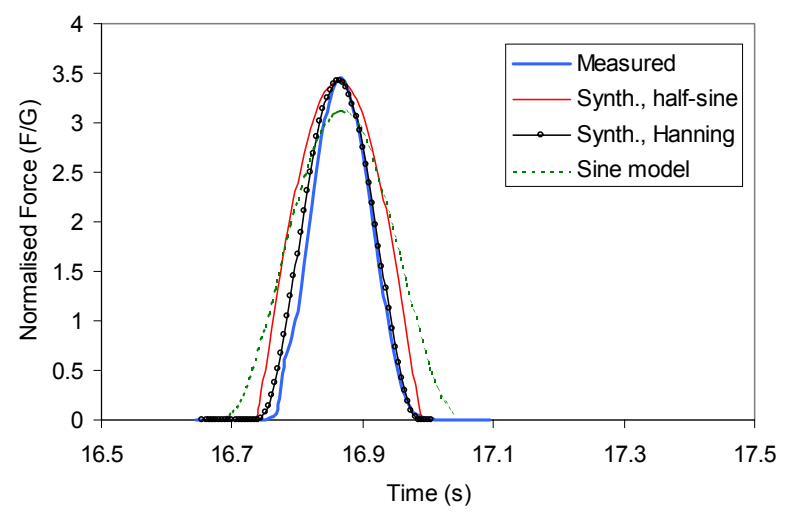

(a)

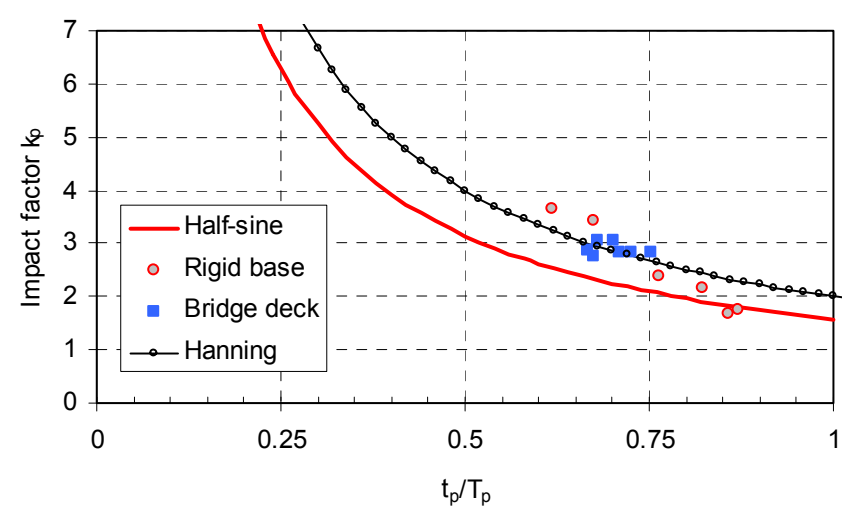

(b)

Fig. 6 (a) Approximation of measured impulse load by half-sine/ Hanning/ sine models; (b) Impact factor: load models vs experimental

Figure $6(\mathrm{a})$ also includes the representation of a simpler load model that is used by some authors, corresponding to a continuous sinusoidal description of the impulse load whose dynamic component is given by

$$
F_{p}(t)=1.56 \cdot G \cdot \sin \left(\frac{2 \pi t}{T_{p}}\right)
$$


This simple load model provides a rough approximation of the measured impulse load. However, the corresponding amplitude is higher than the amplitude in the first harmonic of the impulse load function for the range $2-3.5 \mathrm{~Hz}$. Therefore, it is expected that this function provides a conservative estimate of the impulse load associated with each bridge critical frequency.

In order to understand the effect on the bridge response of the different descriptions of the impulse load, a single degree of freedom system was modelled (with natural frequency of $2.7 \mathrm{~Hz}$, damping ratio of $2 \%$ and modal mass of 30 ton), whose response to a continuous jumping in resonance was calculated, based on the measured load record, as well as on the synthesized records according to the "half-sine" and "Hanning" load models, and on the simple sine model described by (5). The acceleration records represented in Figure 7 show that due to some scatter in the applied load, the response calculated based on the measured impulse record is slightly lower than the response calculated using the fitted load models and is very similar to the one obtained based on the sine load model.

\begin{tabular}{lcc}
\hline Load record & $\begin{array}{c}\text { Peak disp. } \\
(\mathrm{mm})\end{array}$ & $\begin{array}{c}\text { Peak acce. } \\
\left(\mathrm{m} / \mathbf{s}^{2}\right)\end{array}$ \\
\hline Measured & 3.7 & 1.01 \\
Fitted Half-sine & 4.5 & 1.25 \\
Fitted Hanning & 4.1 & 1.11 \\
Sine & 3.8 & 1.04 \\
\hline
\end{tabular}

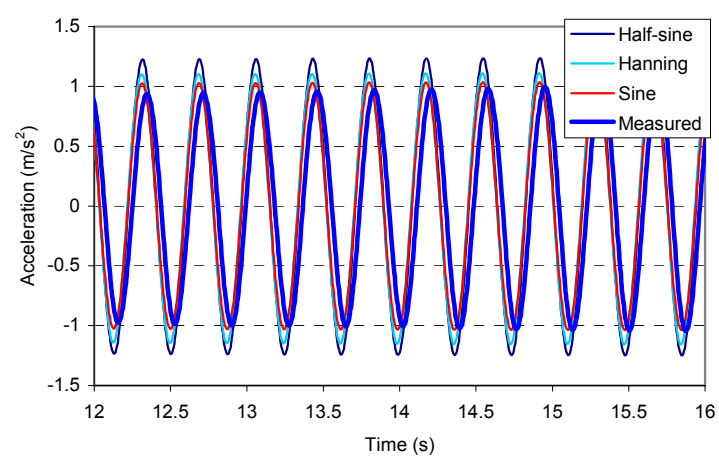

Fig. 7 SDOF response to impulse load at resonance considering different load models

\subsection{Group of pedestrians load model}

The definition of a load model associated with a group of pedestrians requires the specification of the group dimension and of the possible degree of correlation between the various elements. These two critical parameters depend both on the bridge behaviour and on the corresponding dimensions and utilization. A search in the literature shows a wide variation of proposals. Grundmann et al. [10] define an expected maximum acceleration of $0.7-0.8 \mathrm{~g}$. Bachmann et al. [11] propose the consideration of 3 fully synchronised jumping pedestrians, and a recent research by the RWTH Aachen and by SBP Stuttgart in the context of the European Project SYNPEX [12], based on data collected in several lively footbridges, points to the definition of an equivalent sinusoidal modal force $F_{n}(t)$ with a linear amplitude defined as a function of the number of pedestrians in the group $N$, which is extracted based on the known modal mass $M_{n}$, the maximum acceleration $a_{\max , n}$ and estimated damping $\xi_{n}$ of the vibration mode $n$ under evaluation

$$
F_{n}(t)=2 a_{\max , n} \cdot M_{n} \cdot \xi_{n} \cdot \sin \left(2 \pi f_{n} t\right)=\left(C_{1} \cdot N+C_{2}\right) \cdot \sin \left(2 \pi f_{n} t\right)
$$

The simple formula defined above incorporates the synchronisation effects, as well as the variation of damping with the amplitude of vibration. The two effects have been investigated separately within the current study.

Table 3 and Figure 8 systematise measured peak vertical accelerations on various footbridges, as a function of the number of jumping pedestrians. A first conclusion that can be taken is that extremely high accelerations can be attained, the maximum known corresponding to about $2 \mathrm{~g}$, occurring in a $52 \mathrm{~m}$ suspension footbridge in Poland tested by the Wroclaw University under the action of 29 jumping pedestrians.

Considering in particular the FEUP footbridge, it can be noticed that the acceleration grows to a maximum limit of around $1 \mathrm{~g}$ that is reached with a total number of 30 pedestrians. Therefore, a balance seems to be reached that allows for an estimation of an equivalent number of pedestrians necessary to produce this maximum acceleration on a single degree of freedom system, or else the equivalent sine force for analysis.

Using the finite element model described in Section 2, the response to the measured impulse load was calculated and compared to the recorded acceleration, based both on the damping ratios identified from the ambient vibration tests 
displayed in Table 1 and on the corresponding values identified from high amplitude vibration tests. The analysis of Figure 9, showing the three obtained records at mid-span evidences that the stationary component of the response is almost independent from the damping and also that the measured response is much lower than calculated. These results seem to be associated with the slight differences between numerical and identified natural frequencies, conjugated with the fact that the impulse load record shows a dominant frequency of $2.25 \mathrm{~Hz}$, that is closer to the numerical natural frequency excited at mid-span $(2.15 \mathrm{~Hz})$ than to corresponding experimental value $(2.04 \mathrm{~Hz})$.

Table 3 Peak vertical acceleration associated with vandal excitation by groups of pedestrians

\begin{tabular}{|c|c|c|c|c|c|c|c|c|}
\hline \multirow{2}{*}{\multicolumn{2}{|c|}{$\begin{array}{c}\begin{array}{r}\text { Number of } \\
\text { pedestrians }\end{array} \\
1\end{array}$}} & \multirow[t]{2}{*}{ Ruit } & \multicolumn{3}{|c|}{ Eutinger Waagsteg } & \multirow[t]{2}{*}{$\begin{array}{c}\text { Deutsches } \\
\text { Museum }\end{array}$} & \multirow{2}{*}{$\begin{array}{c}\text { FEUP } \\
1.267\end{array}$} & \multirow[t]{2}{*}{ Wroclaw } \\
\hline & & & 1.38 & 0.694 & 2.038 & & & \\
\hline & 2 & 5.384 & 2.242 & 3.835 & 4.323 & & 1.097 & \\
\hline & 3 & 7.42 & 2.349 & 3.57 & 5.587 & & & \\
\hline & 4 & 10.176 & 3.15 & 3.48 & 6.61 & 8.4 & 2.237 & \\
\hline & 4 & & & & & & 2.011 & \\
\hline & 5 & 1.11 & & & & & & \\
\hline & 5 & 9.451 & & & & & & \\
\hline & 5 & 6.317 & & & & & & \\
\hline & 6 & & & & & & 3.064 & \\
\hline & 6 & & & & & & 4.962 & \\
\hline & 8 & & & & & & 6.111 & \\
\hline & 8 & & & & & & 5.989 & \\
\hline & 9 & 11.337 & & & & & & \\
\hline & 10 & & & & & & 5.954 & \\
\hline & 10 & 9.594 & & & & 15.1 & 5.588 & \\
\hline & 10 & & & & & & 5.893 & \\
\hline & 12 & & & & & & 8.017 & \\
\hline & 12 & & & & & & 6.293 & \\
\hline & 14 & & & & & & 6.676 & \\
\hline & 18 & & & & & & 6.319 & \\
\hline & 18 & & & & & & 7.025 & \\
\hline & 18 & & & & & & 5.310 & \\
\hline & 29 & & & & & & & 18.77 \\
\hline & 30 & & & & & & 7.416 & \\
\hline & 30 & & & & & & 8.644 & \\
\hline$\overline{\text { Freq }(\mathrm{Hz})}$ & & 2.55 & 1.25 & 1.27 & 1.95 & & 2.05 & 1.37 \\
\hline$\xi(\%)$ & & $0.8-1.7$ & 0.9 & 0.7 & 0.9 & & $1.4-4.8$ & 1 \\
\hline
\end{tabular}

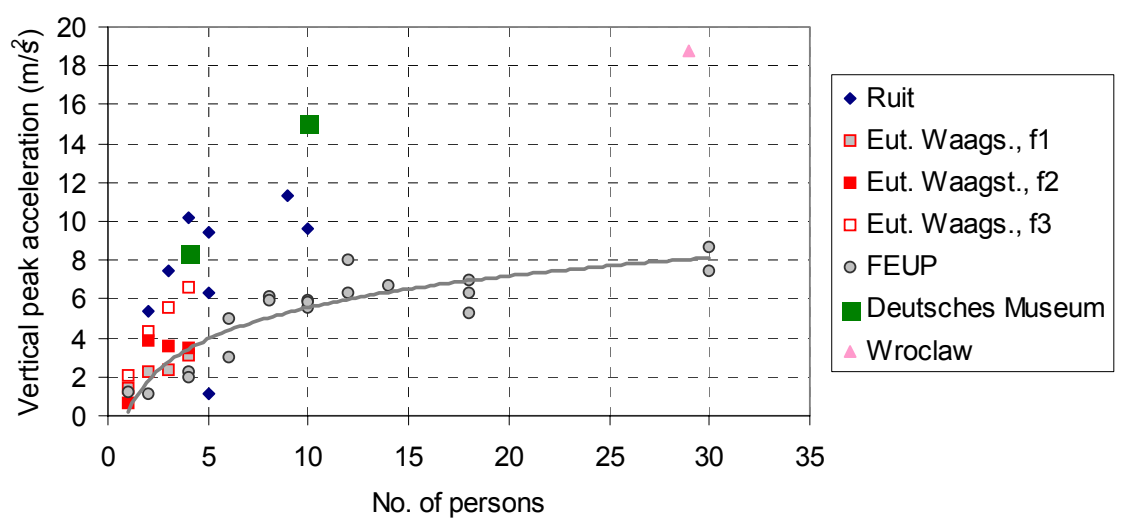

Fig. 8 Variation of peak vertical acceleration with number of pedestrians associated with jumping of a group

The simulation of the resonance condition is therefore developed by a rescaling of the time axis associated with the recorded impulse load and the calculated response is compared to the measured response at $1 / 3^{\text {rd }}$ span for a resonance condition in the second mode of vibration (Fig. 10), leading to very close resonance accelerations, of the order of $1.4 \mathrm{~m} / \mathrm{s}^{2}$ for 1 person jumping. Using this value as reference and comparing to the measured acceleration induced by a varying 
number of pedestrians (Fig. 8), an equivalent number of pedestrians can be calculated, which is displayed in Figure 11. Therefore, based on the current study, the modelling of a group with 30 jumping pedestrians could be done based on the consideration of the input load associated with 6 perfectly synchronised pedestrians, employing the initial damping table for small vibrations. It is noted however that the peak resonant response calculated based on the large damping measurements is $40.5 \%$ the peak response calculated with the initial damping table. A correction accounting for the damping variation should therefore be introduced, which leads to the equivalent number of 13.4 for the group of 30 pedestrians. It is of interest to notice that the ensemble of equivalent number of pedestrians corrected for the identified damping ratios are limited by the straight line represented in Figure 11, defined by

$N_{\text {eq }}=0.4835 \cdot N+1.1383$

where $\mathrm{N}$ represents the number of pedestrians in the group. This line was fitted to the results presented in ref. [9] concerning the measured response of groups of pedestrians jumping on a rigid platform. Further validation of this formula is however required.

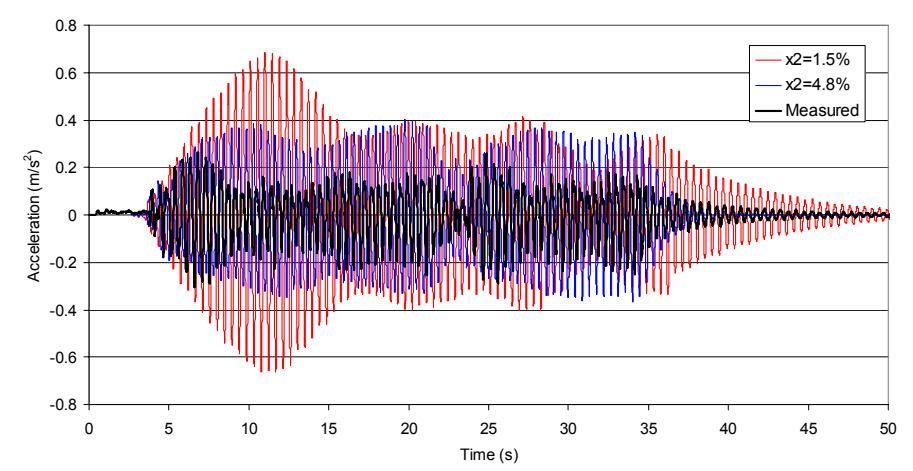

Fig. 9 Calculated vs measured acceleration at mid-span induced by the jumping of one person at that location
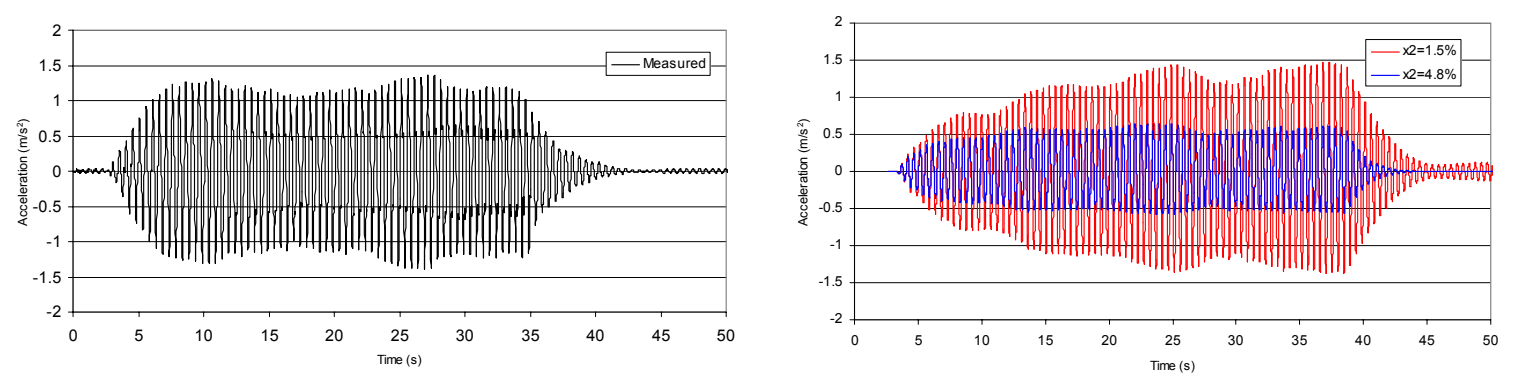

Fig. 10 Calculated and measured acceleration at $1 / 3^{\text {rd }}$ span induced by resonant jumping of one person at that location (2nd mode)

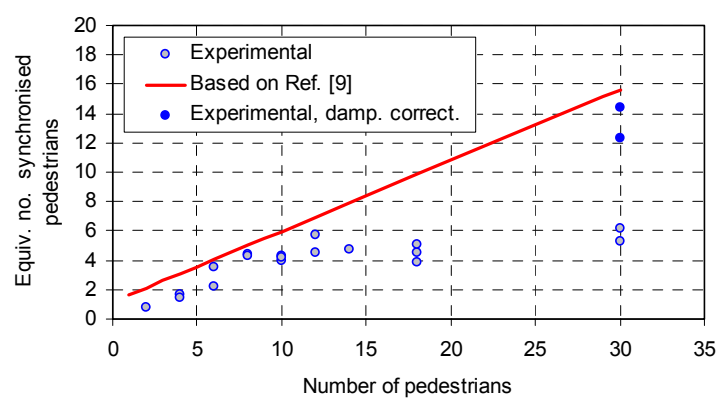

Fig. 11 Equivalent number of pedestrians: FEUP footbridge results and results from [9] 


\section{Footbridge 2005 - Second International Conference}

\section{Conclusions}

The paper presents an experimental and numerical study centred in the definition of load models for vandal excitation on a stress-ribbon footbridge. Recent impulse load measurements for vertical jumping by a single pedestrian have shown to be in agreement with the Bachmann load model. A more precise description based on a Hanning function is however presented, which provides impulse factors better correlated with measurements than the well-known half-sine model. It is shown however that for practical applications the sine representation provides very close estimates of the bridge response to the one measured on the current footbridge.

Considering the load model for group excitation, practical examples have shown that very high amplitudes of acceleration can be attained. The measurement of the resonant response based on a varying number of jumping pedestrians is used to extract an equivalent number of synchronised pedestrians, implying the correction by the ratio between damping factors for low and high amplitude vibrations.

Finally it is of interest to confirm that even for very large accelerations, with peak value of $8.6 \mathrm{~m} / \mathrm{s}^{2}$, the measured dynamic displacements of $53 \mathrm{~mm}$ remain much smaller than the static displacements evaluated for the crowd load of $4 \mathrm{kN} / \mathrm{m}^{2}(0.286 \mathrm{~m})$, meaning that the stresses associated with vandal loads remain inferior to those associated with static loads, as frequently referred in the literature.

\section{Acknowledgements}

The authors are grateful for the collaboration of FEUP students in the performance of the dynamic tests. They thank the data from the Wroclaw footbridge provided by Jaroslaw Zwolski, from Wroclaw University. The support provided by the European Commission in the context of the European Research Project "Advanced Load Models for Synchronous Pedestrian Excitation and Optimized Design Guidelines for Steel Footbridges (SYNPEX)" is fully acknowledged.

\section{References}

[1] WHEELER, J., "Prediction and control of pedestrian induced vibration in footbridges", J. Structural Division, ASCE, Vol. 108, No. ST9, pp. 2045-2065, 1982.

[2] WOLMUTH, B. and SURTEES, J., "Crowd-related Failure of Bridges", ICE, New Civil Engineering International, October 2003, pp. 23-30.

[3] KASPERSKI, M., "The response of pedestrians to lively footbridges", Proc. of the $6^{\text {th }}$ International Conference on Structural Dynamics, EURODYN 2005, Paris, France, Vol. 1, pp. 539-544, 2005.

[4] ENCIL, U.P. Pólo 2, "Passagem para Peões- Projecto Base de Fundações e Estruturas", 1998.

[5] CAETANO, E. and CUNHA, A., "Experimental and Numerical Assessment of the Dynamic Behaviour of a Stress-ribbon Footbridge", Structural Concrete, Journal of FIB, Vol. 5, No.1, pp. 29-38.

[6] CUNHA, A., CAETANO, E., MOUTINHO, C. and MAGALHÃES, F., "Damping Identification in a Stress-ribbon Footbridge", Proceedings of EURODYN 2005, Paris, September 2005.

[7] BACHMANN, H. et al., Vibration Problems in Structures: Practical Guidelines, Birkhäuser Verlag, Basel, 1995, 234pp.

[8] BSI, BS6399 Part 1: Loads for Buildings- Code of Practice for Dead and Imposed Loads. London; UK: British Standards Institution.

[9] FAÍSCA, R., "Characterisation of dynamic loads associated with human activities", PhD. Thesis, Universidade Federal do Rio de Janeiro, Brasil, 2003 (in Portuguese).

[10] GRUNDMANN, H., KREUZINGER, H. \& SCHNEIDER, M., "Schwingungsuntersuchungen für Fußgängerbrücken", Der Bauingenieur 68, 1993 (in German).

[11] BACHMANN, H., PRETLOVE, A. \& RAINER, H., "Dynamic forces from rhythmical human body motions", in Vibrating problems in structures-practical guidelines (appendix G), Birkhäuser Verlag, pp.185-190, 1995.

[12] SYNPEX Semestrial Report no. 4, Contributions from RWTH Aachen and SBP, Nov. 2005. 